\title{
Research Square \\ Removal of Methylene Blue from Aqueous Solution By Polydopamine@Zeolitic Imidazolate-67
}

\section{Maryam Hajnajafi}

University of Guilan

\section{A. Khorshidi ( $\boldsymbol{\nabla}$ khorshidi@guilan.ac.ir)}

University of Guilan https://orcid.org/0000-0002-8990-8052

Ali Ghanadzadeh Gilani

University of Guilan

Francis Verpoort

National Research Tomsk Polytechnic University

\section{Research Article}

Keywords: Adsorption, ZIF-67, Polydopamine, Methylene Blue, Removal

Posted Date: December 16th, 2021

DOI: https://doi.org/10.21203/rs.3.rs-1162284/v1

License: (c) (i) This work is licensed under a Creative Commons Attribution 4.0 International License.

Read Full License 


\title{
Removal of Methylene Blue from aqueous solution by polydopamine@Zeolitic Imidazolate-67
}

\author{
Maryam Hajnajafi ${ }^{a}$, Alireza Khorshidi ${ }^{a}$, , Ali Ghanadzadeh Gilani ${ }^{a}$, Francis Verpoort $^{b, c, d}$ \\ ${ }^{\text {a }}$ Department of Chemistry, Faculty of Sciences, University of Guilan, P. O. Box: 41335-1914, \\ Rasht, Iran

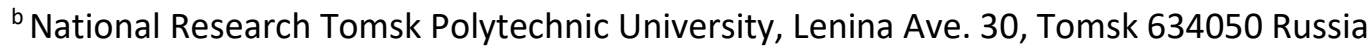 \\ 'Laboratory of Organometallics, Catalysis and Ordered Materials, State Key Laboratory of Advanced \\ Technology for Materials Synthesis and Processing, Wuhan University of Technology, Wuhan, PR China \\ ${ }^{\mathrm{d}}$ Ghent University, Global Campus Songdo, 119 Songdomunhwa-Ro, Yeonsu-Gu, Incheon 406-840, South \\ Korea \\ ${ }^{*}$ Corresponding author's email: khorshidi@guilan.ac.ir
}

\begin{abstract}
Herein, a facile and low-cost route was used to prepare Polydopamine@Zeolitic Imidazolate Framework-67 (PDA@ZIF-67). The structure, morphology, surface functional groups and particle size distribution of PDA@ZIF-67 were studied using FTIR, FESEM, EDS, and BET analyses. The specific surface area and diameter of PDA@ZIF-67 were equal to be $78.203 \mathrm{~m}^{2} / \mathrm{g}$ and $4.179 \mathrm{~mm}$, respectively. The PDA@ZIF-67 was used as an adsorbent for the adsorption of methylene blue dye. The results show that the maximum adsorption efficiency of methylene blue on the surface of PDA@ZIF-67 is achieved at pH 2, the temperature of $65^{\circ} \mathrm{C}, 10 \mathrm{mg}$ of adsorbent, and methylene blue concentration of $7.5 \mathrm{ppm}$.

Moreover, the adsorption process's isothermal, thermodynamic, and kinetics were studied entirely to consider the adsorption mechanism. The methylene blue molecules located in the fine pores of the PDA@ZIF-67 adsorbent determine the adsorption rate. Moreover, the adsorption process of methylene blue at high temperatures is a spontaneous and endothermic reaction. The adsorption efficiency of PDA@ZIF-67, after the recovery, reached 62.21\%, which is an excellent advantage for using this adsorbent.
\end{abstract}


Keywords: Adsorption; ZIF-67; Polydopamine; Methylene Blue; Removal.

\section{Introduction}

Rapid growth of chemical industries along with the expansion of agriculture has led to severe pollution of water resources [30]. This topic is considered as a global problem [11]. Among the various types of water pollutants, dyes have emerged as one of the most important pollutants in the scientific community [35].

Methylene blue (MB) with the molecular formula of $\mathrm{C}_{16} \mathrm{H}_{18} \mathrm{ClN}_{3} \mathrm{~S}$ is an organic cationic dye, which has been widely used in biology and chemical applications. Large amounts of organic dye effluents are produced annually by related industries such as printing, textiles, dyeing, papermaking, and so on. Colored effluents have undesirable properties such as high BOD, poor biodegradation, toxic nature, etc. These properties are dangerous to living organisms as well as photosynthesis of microorganisms [12].

Up to date, various approaches such as advanced oxidation process (AOP) [41], membrane filtration [39], flocculation [42], ozonation [16], photocatalytic degradation [36], biodegradation[31], membrane technology [1] and coagulation [2] have been used to remove organic pollutants from aqueous phase. However, application of traditional methods still faces two inherent limitations including complexity and economic inefficiency. Therefore, finding an easy, economical and effective method for wastewater treatment has emerged as a hot topic in scientific community. Adsorption on the surface of a suitable adsorbent is another common method for removal of different contaminants. Carbon materials [23, 30], minerals (including kaolinite and montmorillonite) [18], polymers [10] zeolites [37], clays [8], sludge [5], flax fibers [40], and Biochar [33], are some of the most widely used adsorbents in this regard.

However, poor performance of the conventional adsorbents in terms of selectivity and capacity has been emerged as a fundamental problem. In recent years, metal-organic frameworks (MOFs) due to their high porosity and surface area, large adsorption capacity, and desirable guest-host interactions, have been employed as a promising alternative in various applications such as drug delivery, adsorption processes [46], batteries, gas storage, and separation [9, 17, 29, 46]. High adsorption capacity of the MOFs has been attributed to the electrostatic interactions, conjugated $\pi-\pi$ interactions and hydrogen bonds. Since the MOFs show good thermal and chemical stability, they have been used in various fields such as gas adsorption, molecular separation and electrochemistry. One of the most studied metal organic frameworks is the Zeolitic Imidazolate67 (ZIF-67), which consists of $\mathrm{Co}^{2+}$ ions linked by 2-methylimidazolate to form a cubic crystal structure with the unit cell parameters of $a=b=c=16.9585 \AA$. Zeolitic Imidazolate- 67 offers a three-dimensional (3D) structure with a high tendency to adsorb contaminants in the aqueous media. However, the application of ZIF-67 as an adsorbent still faces three vital problems including low specific surface area, poor structural stability, and difficult separation. 
Dopamine (3,4-dihydrophenylamine) is a neurotransmitter that plays a neurological role in the body and brain. This organic compound is naturally synthesized in plants and animals (kidneys and brain) [17]. Dopamine consists of a catechol unit attached to an amine unit by an ethyl chain and will be easily solved in many solvents due to its polar functional groups[29].

One of the derivatives of dopamine is polydopamine (PDA) [25]. The unique properties of PDA (size control, uniform spherical shape, thermal stability, good biocompatibility and non-toxicity) leads to its application in various fields [34]. Moreover, the presence of NH and catechol groups in PDA leads to the application of this compound as an active adsorbent. Recently, scientists have proven that some polymers can be utilized as an effective adsorbent for the absorption of pollutants such as dyes. A porous magnetic carboxylic polymer as an efficient adsorbent for wastewater treatment was reported by Huang et al [21]. Zhang and co-workers modified a cationic magnetic chitosan grain polymer for efficient adsorption of heavy metals and dyes in a wide range of $\mathrm{pH}$ [47]. In recent years, scientists have found that the polymer-doped ZIF-67 can be utilized to overcome the above mentioned challenges. Owing to the -OH functionality and its hydrophilic nature, PDA can be easily used as a dopant for ZIF-67, to provide a readily dispersible composite material. It has been shown that the porous structure of the PDA does not block the ZIF-67 holes[32].

In this contribution, preparation and application of a new hybrid material consisting of ZIF-67 and PDA is reported. The PDA@ZIF-67 was used as an efficient adsorbent for removal of MB dye from aqueous solution. Effect of various parameters on the adsorption of MB, including the reaction time, initial dye concentration, absorbent dosage, $\mathrm{pH}$, temperature, and PDA:ZIF-67 ratio was studied, as well as the kinetics and thermodynamics of the adsorption process.

\section{Experimental}

\subsection{Chemicals}

All of the chemicals and reagents were purchased as received. $\mathrm{Co}\left(\mathrm{NH}_{3}\right)_{2} \cdot 6 \mathrm{H}_{2} \mathrm{O}$, 2Methylimidazole, $\mathrm{MB}$, Ethanol, $\mathrm{KMnO}_{4}$, and $\mathrm{K}_{2} \mathrm{Cr}_{2} \mathrm{O}_{7}$ were purchased from Merck. Dopamine (DA, 3,4-dihydroxyphenethyl amine) was purchased from Caspian Tamin pharmaceutical Company. Double distilled water was used as solvent in all of the experiments.

\subsection{Instrumentation}

Ultraviolet-visible (UV-Vis) spectra were recorded at room temperature (RT) by using a Cary 5000 spectrophotometer. Energy-dispersive X-ray spectroscopy (EDS) was performed with a Mira-3 XMu. Morphology of the PDA@ZIF-67 sample was studied by scanning electron 
microscopy (SEM, XL30 ESEM; Philips). BET measurements were performed on a BEL SORP mini II. A Milwaukee Mi806 pH-meter was used in all of the experiments.

\subsection{Synthesis of ZIF-67}

ZIF-67 nanocubes were prepared via a simple method in aqueous solution at room temperature (RT) according to the literature [28].

\subsection{Synthesis of PDA@ZIF-67}

First, $30 \mathrm{mg}$ of ZIF-67 was dispersed in a solution of $45 \mathrm{mg}$ of polydopamine in $30 \mathrm{~mL}$ of double distilled water in an ultrasonic bath. Afterwards, $\mathrm{KMnO}_{4}$ (in excess, a full spatula) was added and stirred for $6 \mathrm{~h}$. Then the white precipitate was washed with water and ethanol several times, and dried at $50{ }^{\circ} \mathrm{C}$ overnight. Potassium permanganate was used as a polymerization initiator and the main oxidant to convert dopamine to polydopamine [34]

\section{2-5 Recycling of the PDA@ZIF-67}

Recovery and reuse of the PDA@ZIF-67 composite was performed as follows: after the first cycle, the PDA@ZIF-67 composite was separated by centrifugation at $3000 \mathrm{rpm}$, and washed several times with water and then with eethanol. Finally, the precipitate was dried in an oven at $50{ }^{\circ} \mathrm{C}$ overnight. The recycled PDA@ZIF-67 was used consecutively for six cycles.

\section{Batch adsorption studies}

To $100 \mathrm{~mL}$ of $2.5 \mathrm{ppm}$ solution of MB in double distilled water, $10 \mathrm{mg}$ of PDA@ZIF-67 was added, and the mixture was stirred constantly by a magnetic stirrer. The progress of adsorption was studied at different time intervals by sampling and filtration of the solution, followed by measuring the absorbance of the filtrate at $664 \mathrm{~nm}$.

$\mathrm{pH}$ of the solutions was adjusted to the desired value by using Britton-Robinson buffer, which is a universal $\mathrm{pH}$ buffer used for the $\mathrm{pH}$ range from 2 to 12 [7]. The chemical structure of methylene blue is shown in Figure 1. 


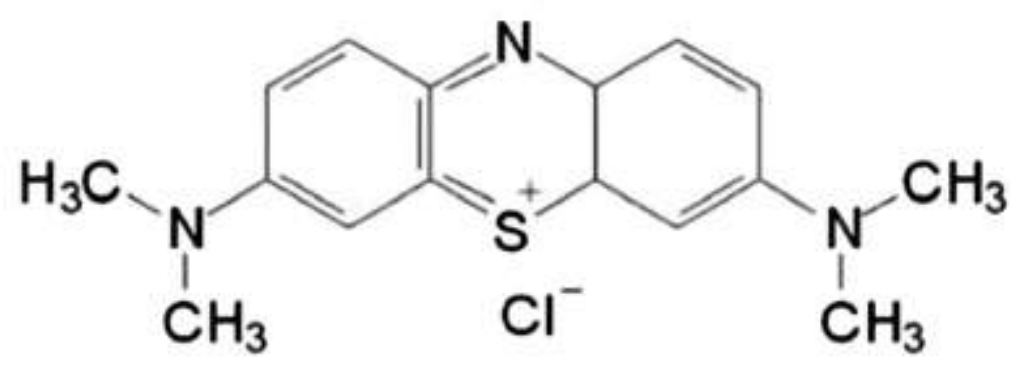

Figure 1- Chemical structure of methylene blue

\section{Results and discussion}

Structural characterization of the adsorbent was carried out by FTIR and FESEM analyses. Figure 2a displays the FTIR spectrum of ZIF-67. Generally, the adsorption peaks in the range of $600-1500 \mathrm{~cm}^{-1}$ are attributed to the stretching and bending vibrations of imidazolate moiety [22]. The observed peak at $1578 \mathrm{~cm}^{-1}$ is attributed to the stretching vibration of $\mathrm{C}=\mathrm{N}$ [27]. Also, the adsorption peak at $3135 \mathrm{~cm}^{-1}$ is related to the $\mathrm{C}-\mathrm{H}$ bonds of the aromatic ring of 2methylimidazole. Figure $2 \mathrm{~b}$ shows the FTIR spectrum of PDA. The advent of large and wide peak in the range of 3200-3600 $\mathrm{cm}^{-1}$ well corroborates the presence of hydroxyl groups [19]. The adsorption peaks of amine functional groups are not seen in this spectrum due to overlapping of the intense hydroxyl peak [6]. The N-H bending vibrations, however, were observed at $1621 \mathrm{~cm}^{-}$ ${ }^{1}$. The $\mathrm{C}=\mathrm{C}$ vibrations of the PDA structure were appeared at $1504 \mathrm{~cm}^{-1}$. Figure $2 \mathrm{c}$, on the other hand, represents the FTIR spectrum of the PDA@ZIF-67. One can note that the corresponding peaks of the anticipated functional groups are present in the final product, without considerable changes in their position and intensity. 


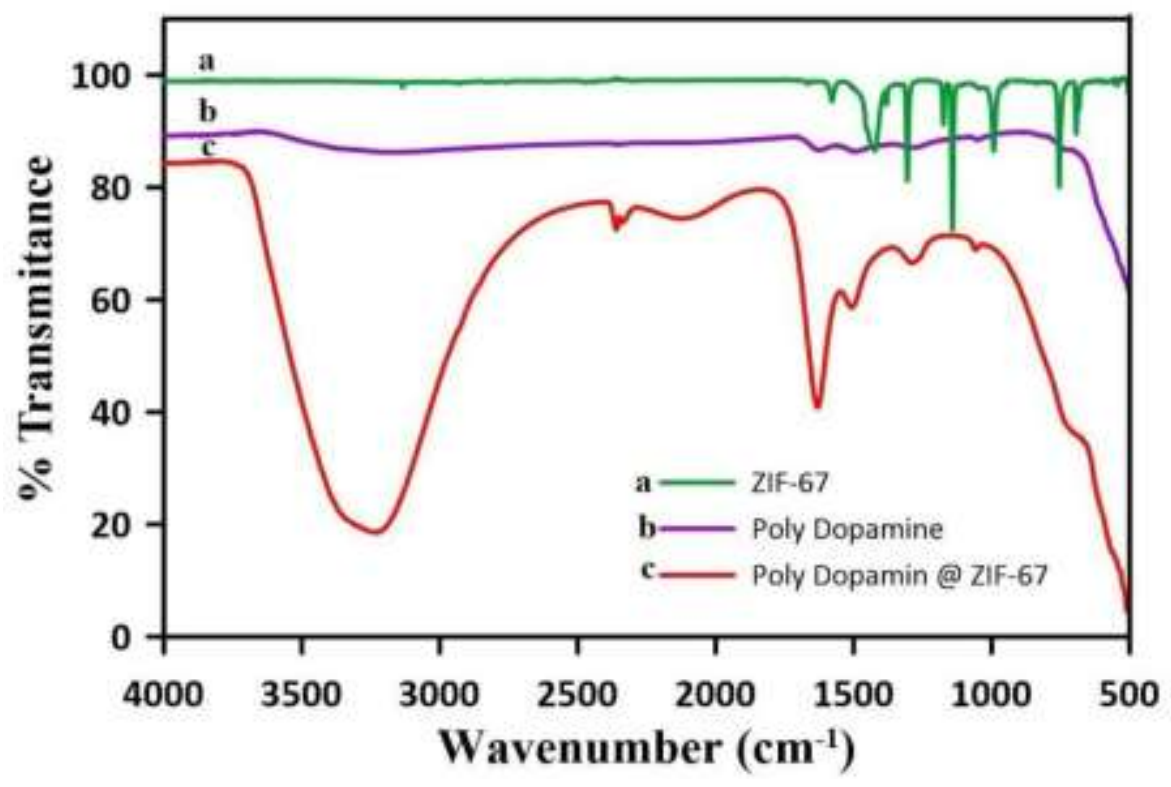

Figure 2- FT-IR spectra of (a) ZIF-67, (b) polydopamine, and (c) PDA@ZIF-67 composite.

Morphological study of the PDA@ZIF-67 was carried out by FESEM. Surface morphology of the PDA@ZIF-67 composite is shown in Figure 3. Clearly, the PDA@ZIF-67 composite is formed of many ultrafine nanoparticles in the range of $12-18 \mathrm{~nm}$. 


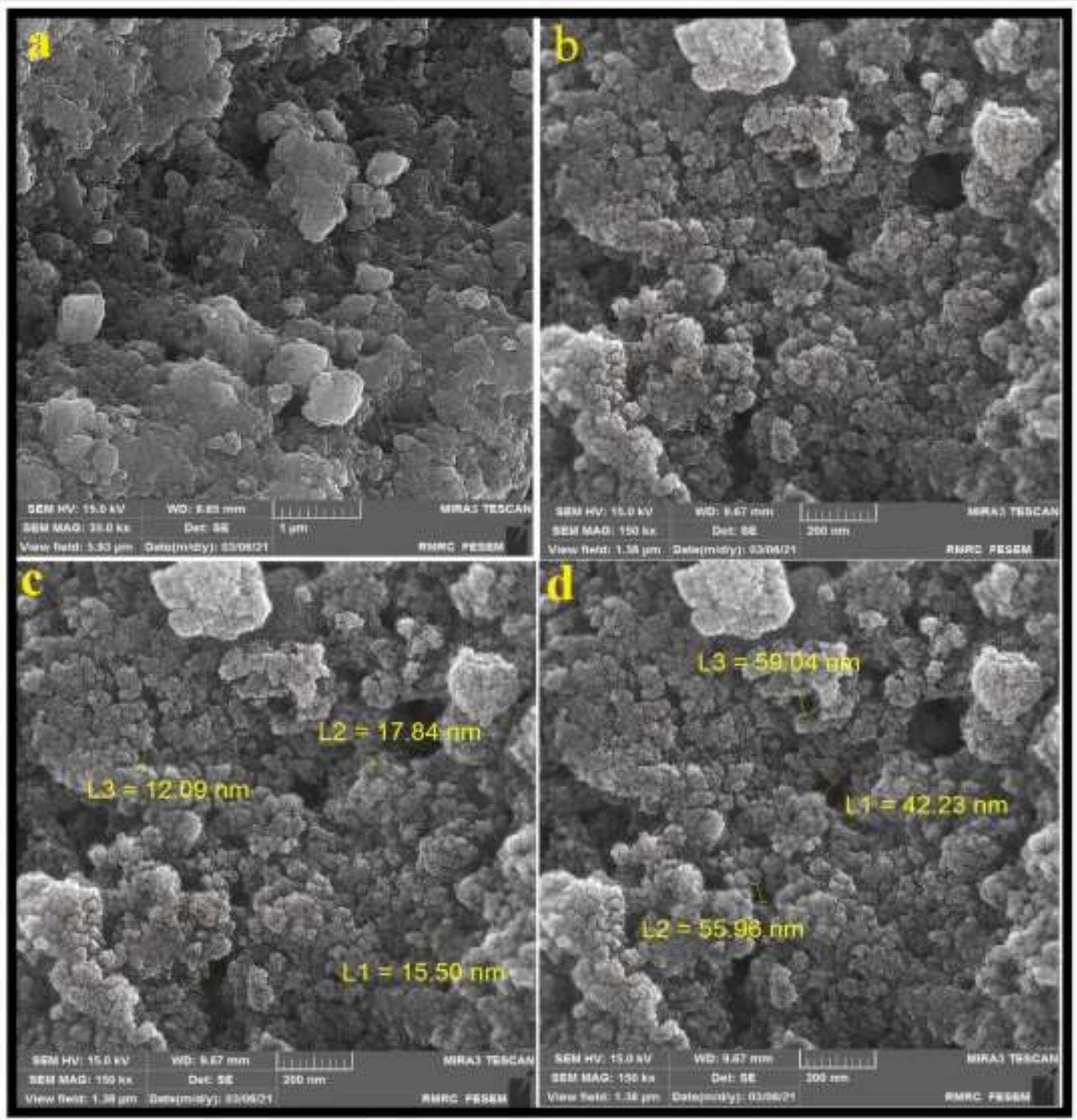

Figure 3- FESEM images of the PDA@ZIF-67 composite

EDS analysis was also used to evaluate the composition of the constituting elements of the PDA@ZIF-67. As shown in Figure 4, the corresponding K and L lines of each of the anticipated elements were present, with the C:Co ratio of $26.3: 1.3 \% \mathrm{w} / \mathrm{w}$. 


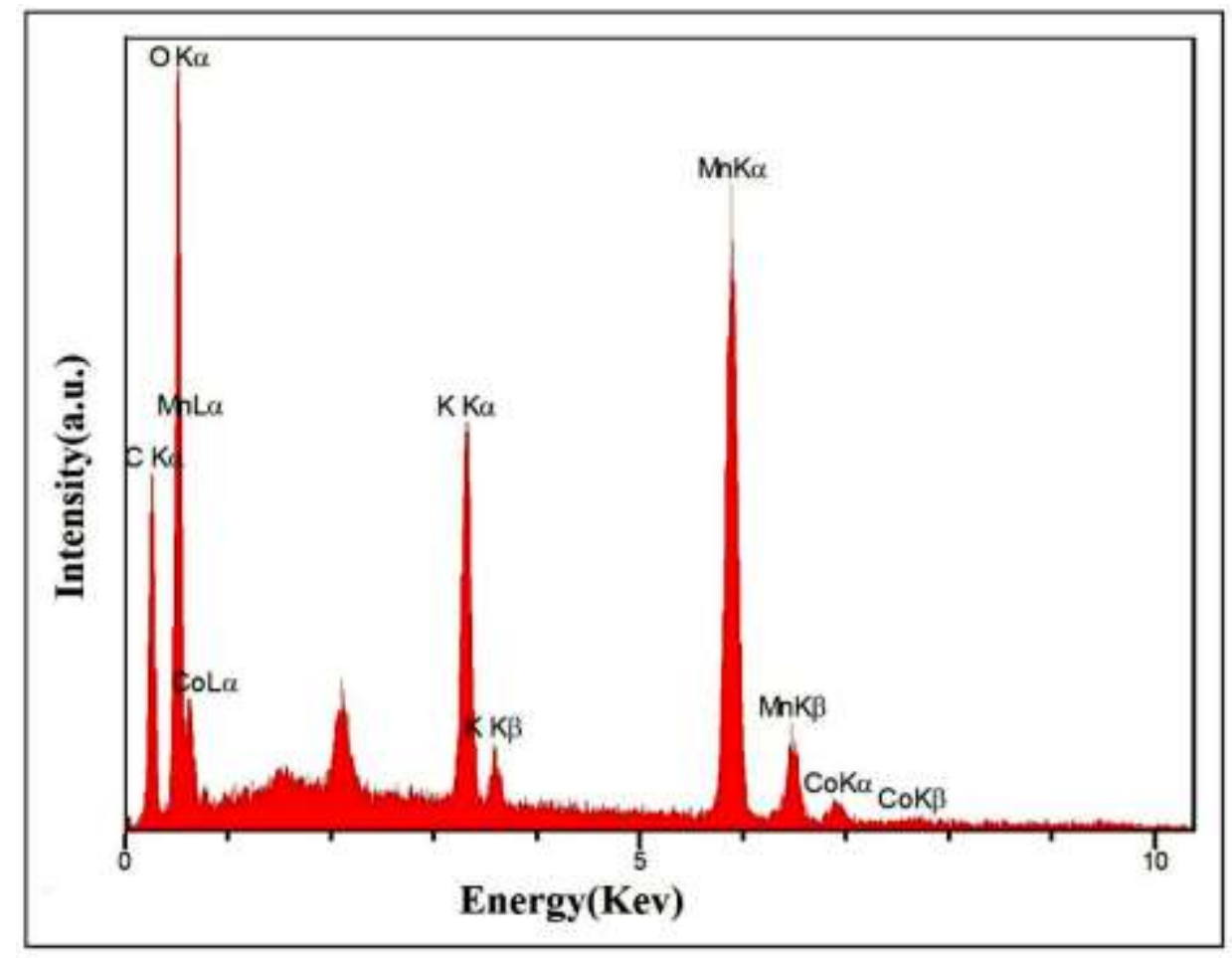

Figure 4- EDS spectrum of the PDA@ZIF-67 composite

BET analysis was used to study the physicochemical properties of PDA@ZIF-67 composite. The corresponding $\mathrm{N}_{2}$ adsorption-desorption isotherm is shown in Figure 5a, where a type-IV isotherm is clearly visible with a distinct hysteresis loop in the $P / P_{0}$ range of $0.3-0.95$. The specific surface area of the PDA@ZIF-67 was found to be $203.78 \mathrm{~m}^{2} \cdot \mathrm{g}^{-1}$. The corresponding BJH pore distribution curve (Figure 5b) was used to evaluate the pore structure of PDA@ZIF-67. As can be seen, two types of pores including micro- $(<2 \mathrm{~nm})$ and meso-pores $(2-50 \mathrm{~nm})$ were present with an average pore diameter of $4.179 \mathrm{~nm}$. 

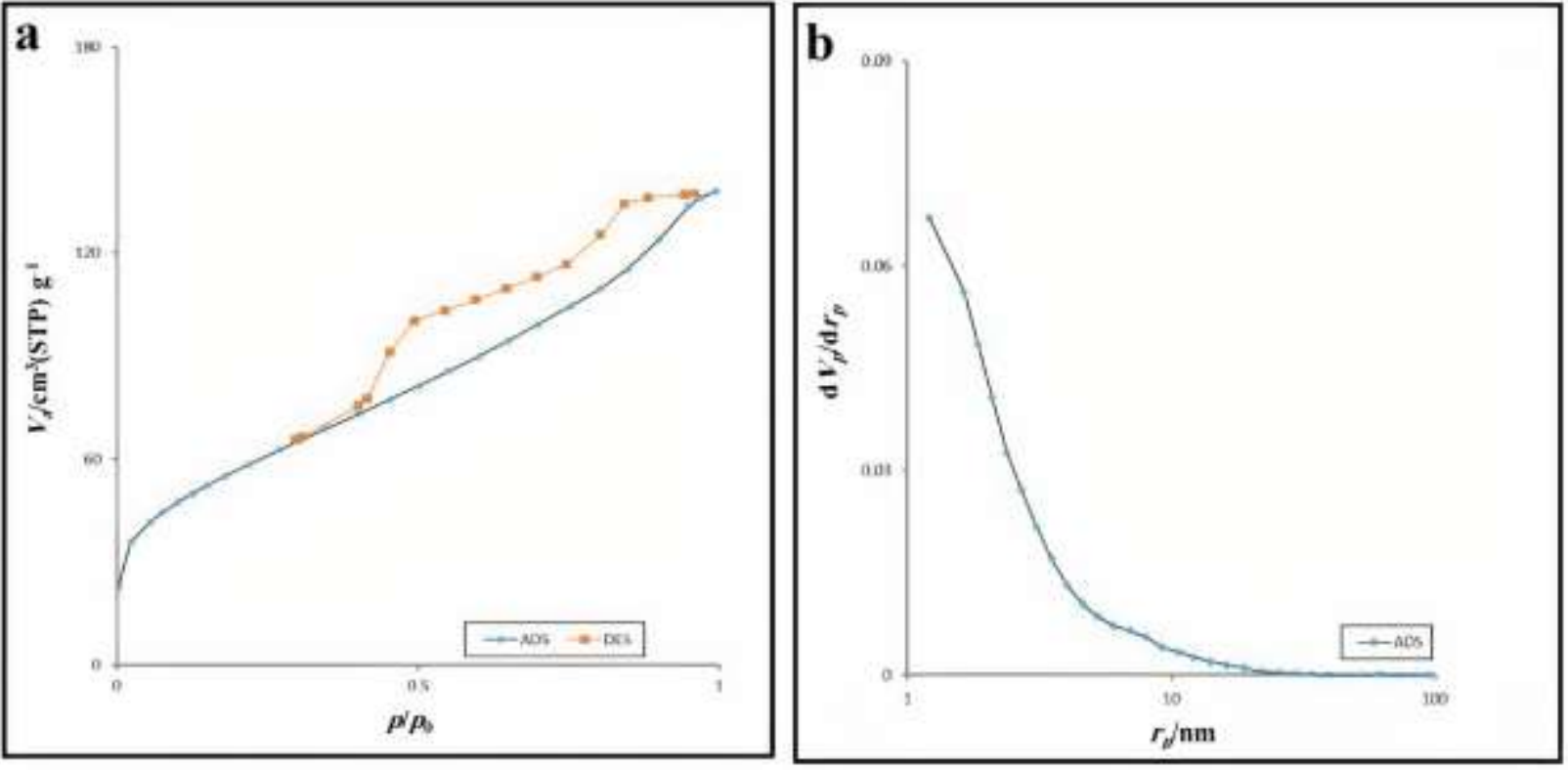

Figure 5-(a) The N2 adsorption-desorption isotherm of PDA@ZIF-67, and (b) its corresponding BJH pore distribution curve

With the characterized PDA@ZIF-67 composite in hand, a systematic study was conducted to evaluate its adsorption capacity. First, we compared the adsorption efficiency of MB on polydopamine, Zeolitic Imidazolate-67 and PDA@ZIF-67 composite. To do so, a 2.5 ppm solution of $\mathrm{MB}$ in double distilled water was prepared. $10 \mathrm{mg}$ of each adsorbent was added to $100 \mathrm{~mL}$ of the aforementioned solution. Up to $99 \%$ of MB removal was observed within 45 minutes by using the PDA@ZIF-67 synthesized in presence of potassium permanganate as a polymerization agent (to convert dopamine to polydopamine during the synthesis of PDA@ZIF67). In comparison, $\mathrm{K}_{2} \mathrm{Cr}_{2} \mathrm{O}_{7}$ as the polymerization initiator, was not as effective as $\mathrm{KMnO}_{4}$.

Figure 6 shows the trend of $\mathrm{MB}$ adsorption in terms of $C / C_{0}$ vs. time for each of the adsorbents, where, $C_{0}$ is the initial concentration of dye solution, and $C$ is its concentration at time t. As shown, the PDA@ZIF-67 can remove up to $99 \%$ of $\mathrm{MB}$ within 45 min using $\mathrm{KMnO}_{4}$ (as a polymerization initiator) at RT and neutral $\mathrm{pH}$. 


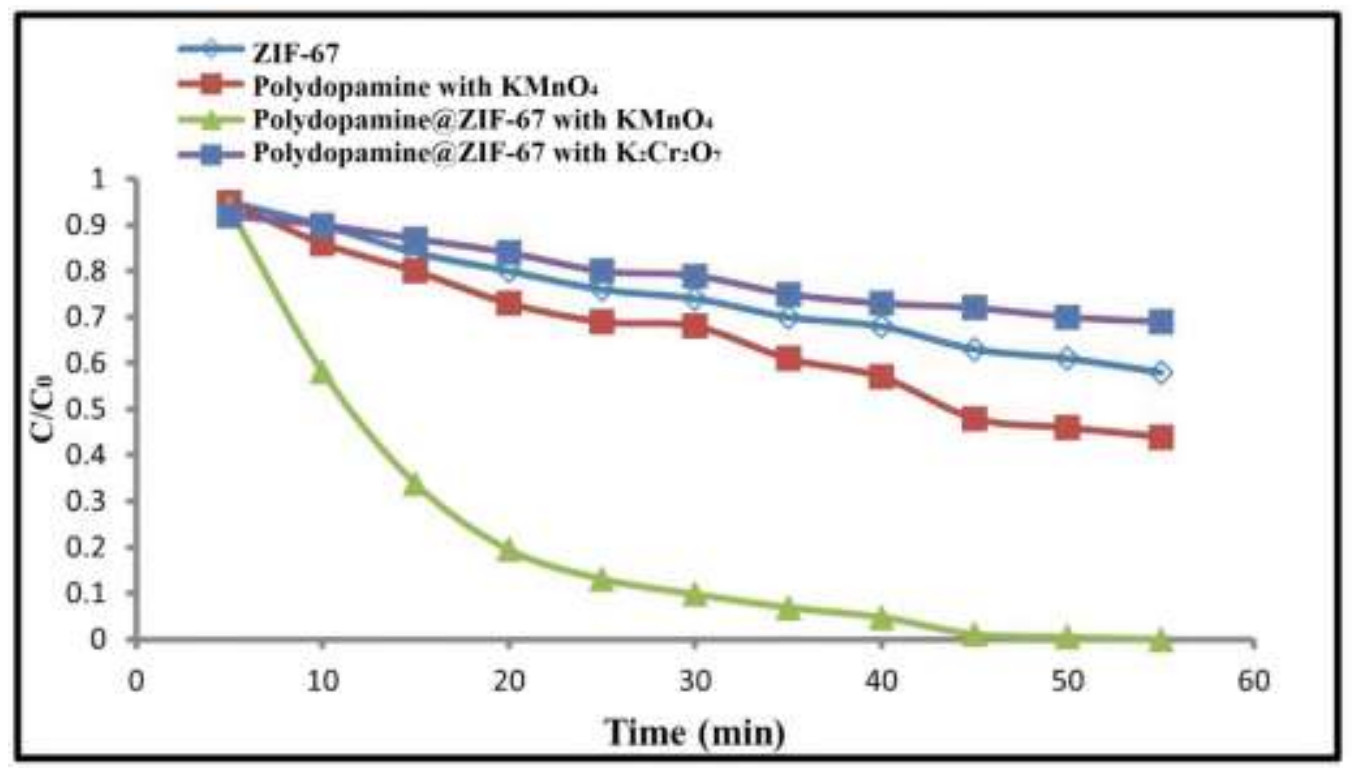

Figure 6- The adsorption process of $\mathrm{MB}(2.5 \mathrm{ppm})$ over time in the presence of $10 \mathrm{mg}$ of each adsorbent at RT and neutral pH

In order to optimize the polydopamine/ZIF-67 ratio, various proportions of each ingredient was studied. It was found that the optimal ratio of polydopamine to ZIF-67 was 45:30 (mg) as shown in Figure 7. 


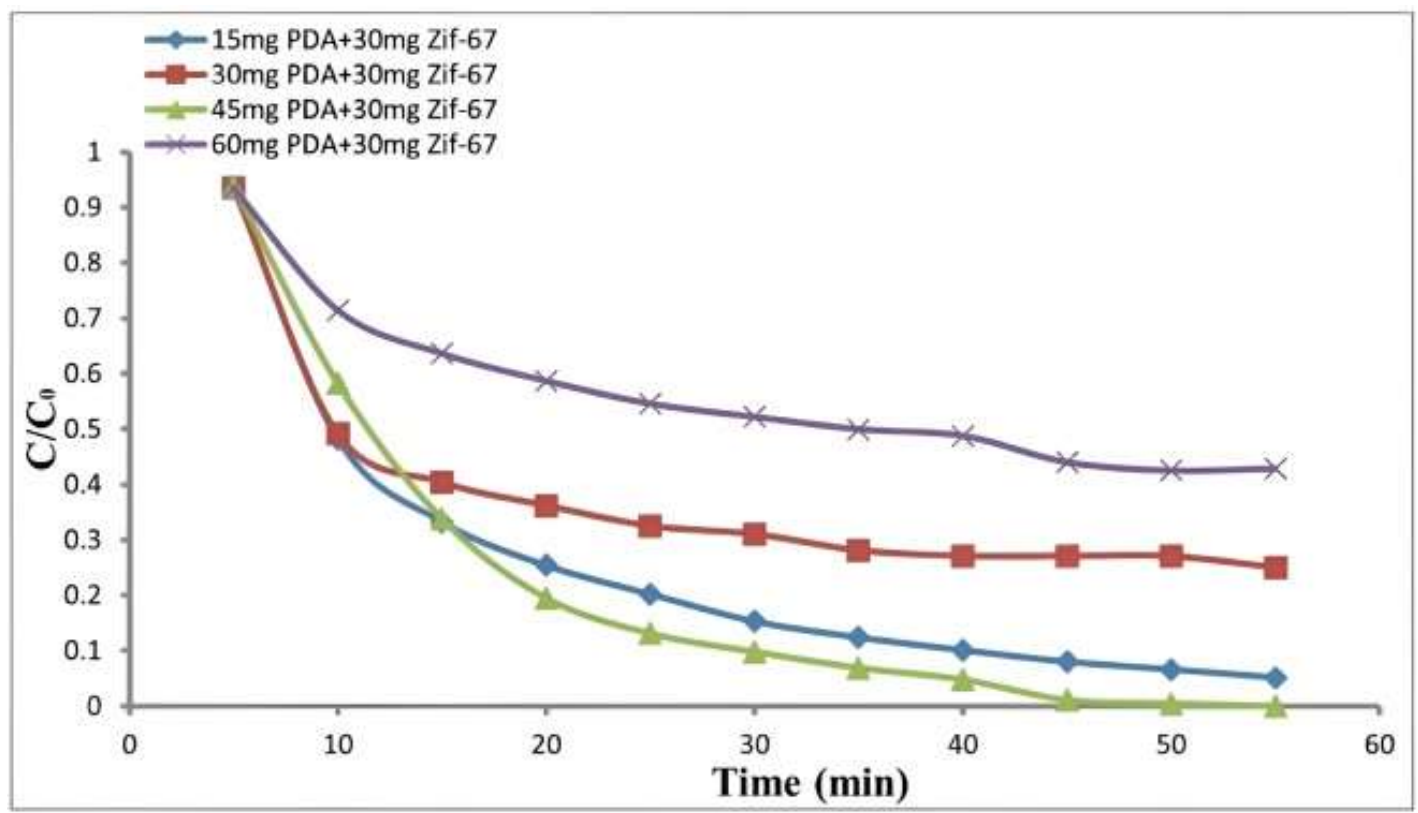

Figure 7- The adsorption process of $\mathrm{MB}(2.5 \mathrm{ppm})$ over time in the presence of $10 \mathrm{mg}$ adsorbent synthesized with different polydopamine: ZIF-67 ratios at RT and neutral $\mathrm{pH}$

One of the key factors in the adsorption processes is the $\mathrm{pH}$ of solution. In this study, the BrittonRobinson buffer (Aka BBR or PEM) was used to adjust the $\mathrm{pH}$ in the range of 2-12, to study the effect of $\mathrm{pH}$ on the adsorption of $\mathrm{MB}$ [38]. Figure 8 illustrates the UV-Vis spectra of MB in presence of $10 \mathrm{mg}$ of the composite at different $\mathrm{pH}$ values $(2,4,6,8,10$, and 12). As shown, the maximum adsorption efficiency was obtained at $\mathrm{pH} 2$, where the solution is almost completely colorless. As predicted, the adsorbent at the negative $\mathrm{pH}(\mathrm{pH}<0)$ has a positive charge due to the protonation of the hydroxyl groups, so that the adsorption capacity at high acidic $\mathrm{pH}$ cannot be maximum. This observation is due to the fact that electrostatic interactions are not the dominant force in $\mathrm{MB}$ at $\mathrm{pH}$ 2. In fact, a high adsorption capacity for $\mathrm{MB}$ in the $\mathrm{MB}^{+}$form in acidic environment is obtained due to the $\pi-\pi$ interactions, or formation of hydrogen bonds (Co-$\mathrm{OH} . . . \mathrm{NH})$ between the MB and PDA@ZIF-67 catalyst [45]. 


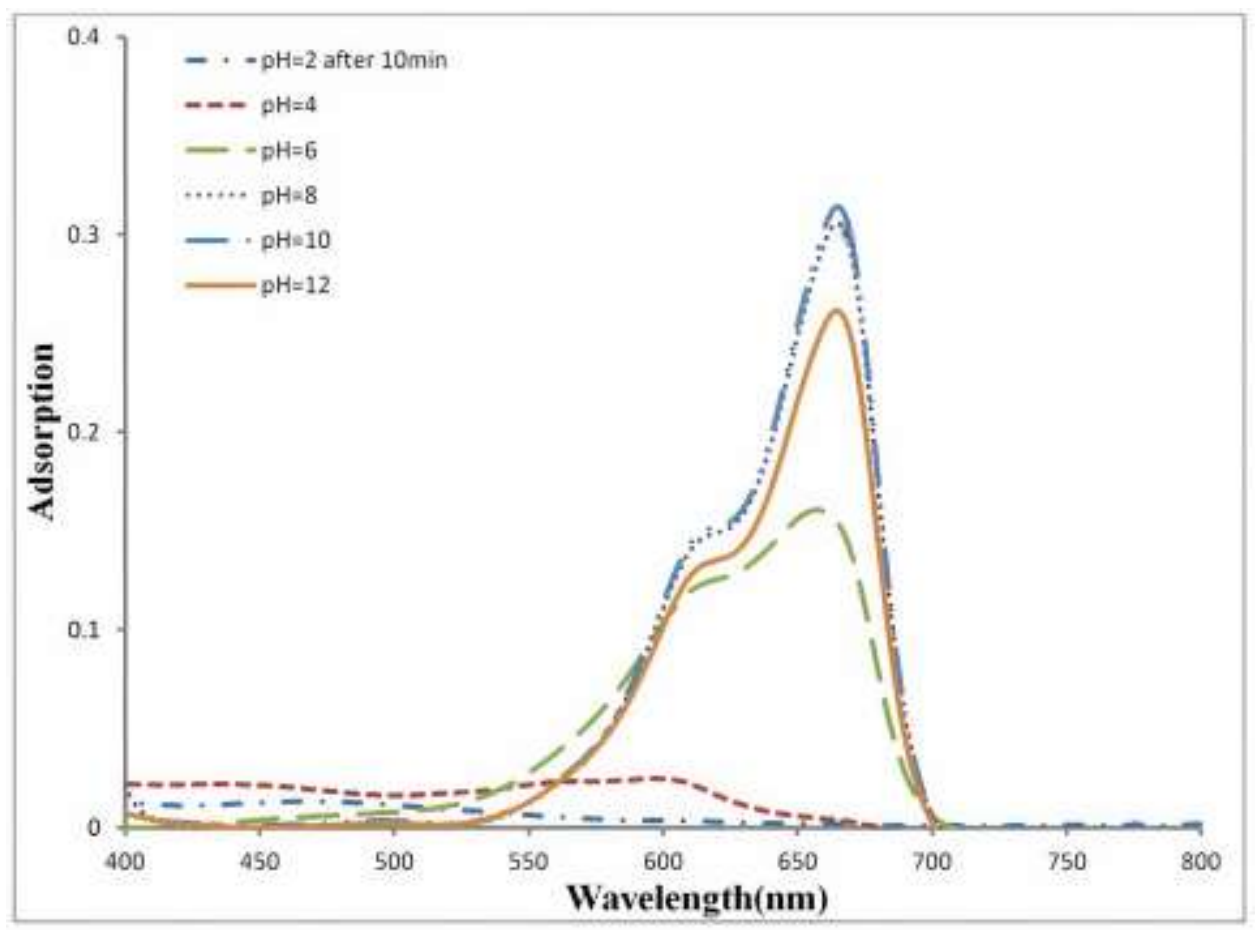

Figure 8- Trend of MB (2.5 ppm) adsorption on 10 mg of PDA@ZIF-67 after 10 min at different pH values

Effect of the initial dye concentration on the adsorption process was also studied in presence of 10 mg of PDA@ZIF-67 to determine the optimal concentration of MB. All of the experiments were conducted at RT and $\mathrm{pH} 2$ for 10 minutes. The corresponding UV-Vis spectra are shown in Figure 9, and the results are summarized in Table 1. According to the data of Table 1 and Figure 9, the optimal concentration of $\mathrm{MB}$ was determined as $7.5 \mathrm{ppm}$.

Table 1. The adsorption percentage of different concentrations of MB dye for 10 minutes at $\mathrm{pH} 2$

\begin{tabular}{cc}
\hline MB concentration $(\mathrm{ppm})$ & Adsorption efficiency $(\%)$ \\
\hline 2.5 & 94.61 \\
5 & 93.13 \\
7.5 & 89.64 \\
10 & 72.91 \\
15 & 65.84 \\
20 & 47.76 \\
\hline
\end{tabular}




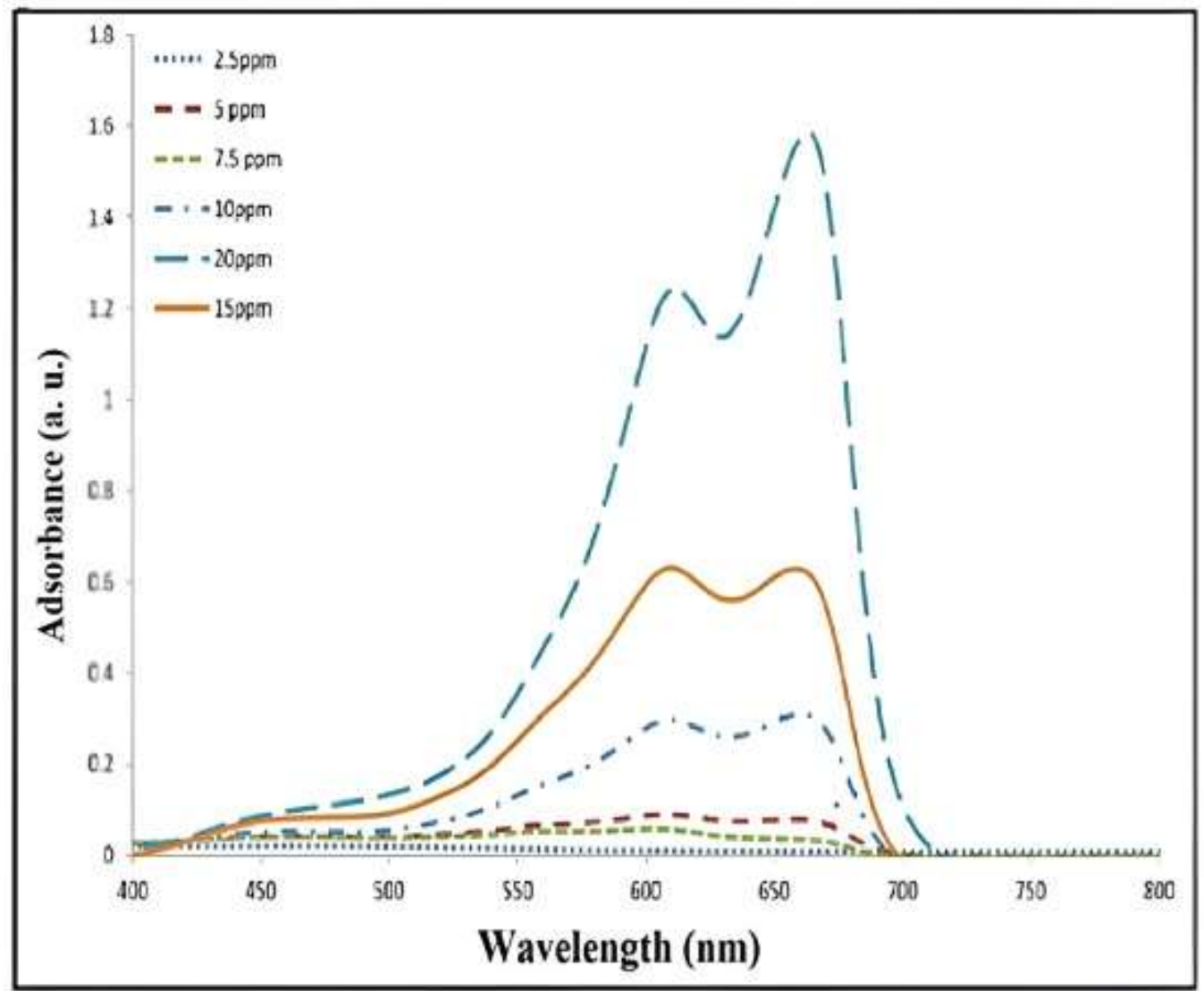

Figure 9- The UV-Vis spectra of MB dye solutions with different concentration after 20 min at $\mathrm{pH}=2$

To determine the optimal contact time, the adsorption process of MB (7.5 ppm) was performed at $\mathrm{RT}$ and $\mathrm{pH}=2$ in presence of $10 \mathrm{mg}$ of the adsorbent from 2 to $8 \mathrm{~min}$. As shown, the optimal contact time for this situation, was found to be 8 min. with up to $99.98 \%$ of dye removal. 


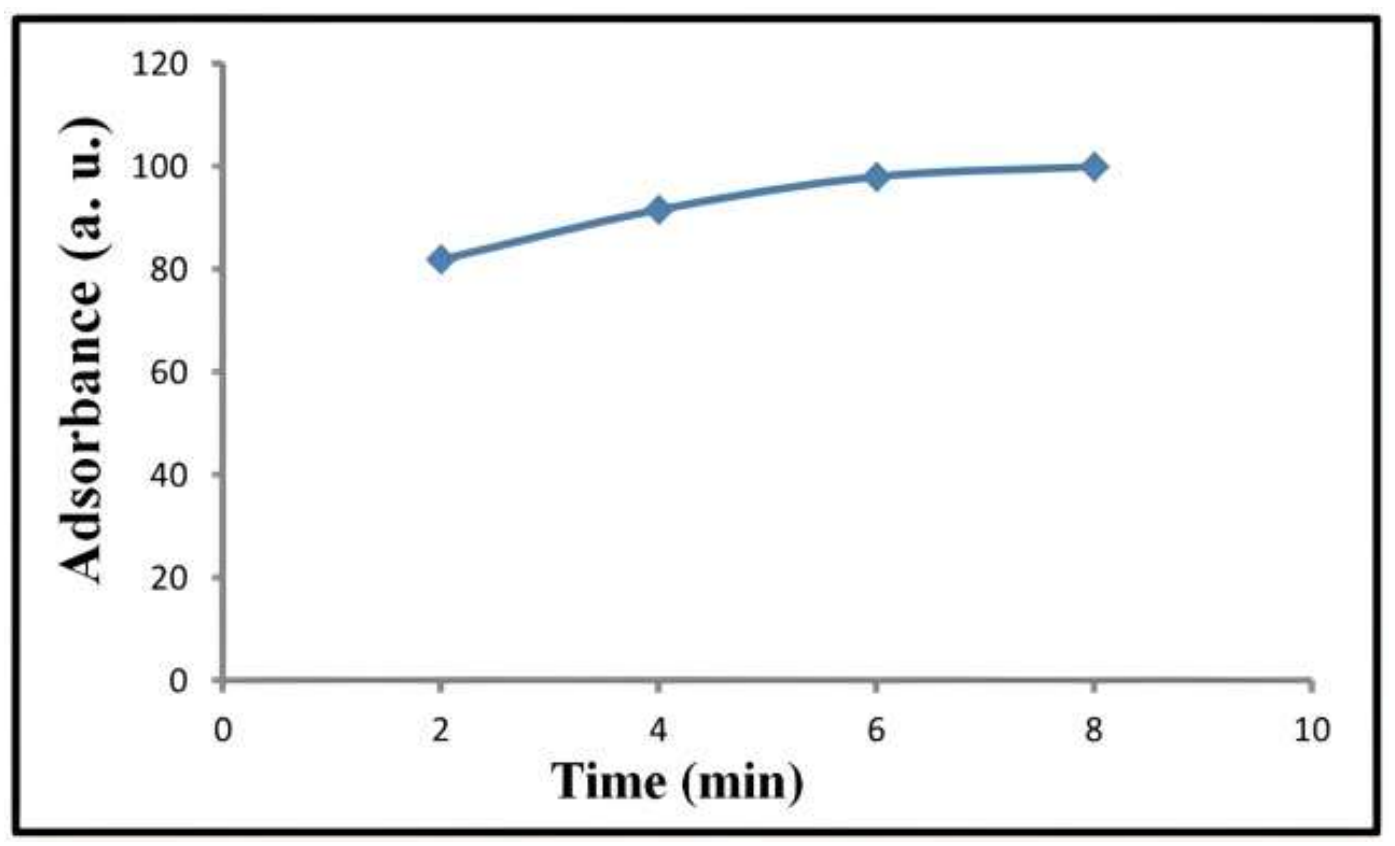

Figure 10- Effect of contact time on the adsorption process of MB dye

Eventually, the optimum temperature for the adsorption of $\mathrm{MB}$ was determined by studying the adsorption reaction at four different temperatures from $25^{\circ} \mathrm{C}$ to $65^{\circ} \mathrm{C}$. The obtained results are illustrated as Figure 11, where one can see that the adsorption of MB (100 mL, $7.5 \mathrm{ppm})$ after 8 min is maximum at $65^{\circ} \mathrm{C}$ in presence of $10 \mathrm{mg}$ of PDA@ZIF-67 at pH 2. 


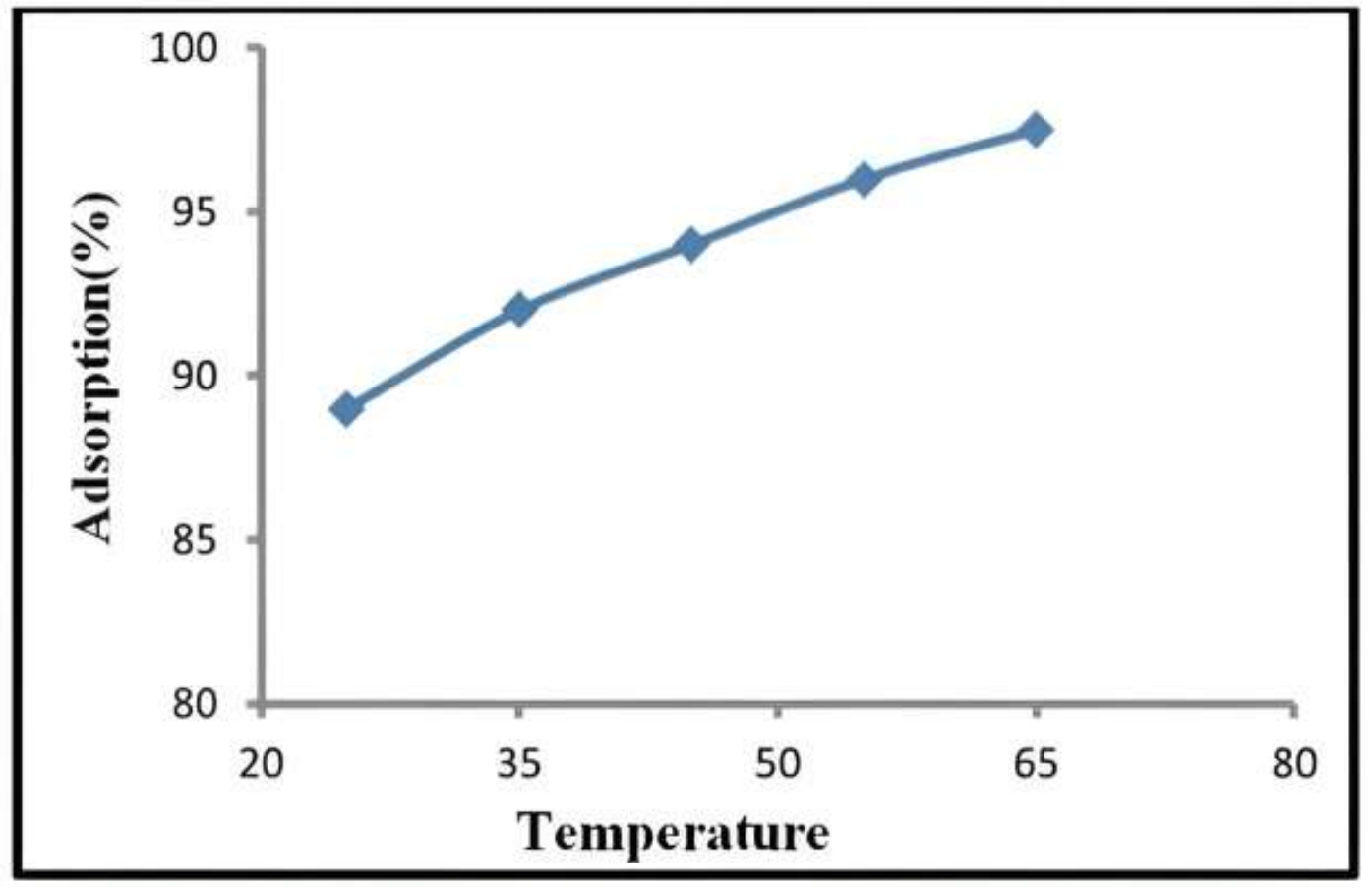

Figure 11- Effect of temperature on the removal of $\mathrm{MB}(7.5 \mathrm{ppm}, \mathrm{pH} 2)$

\section{Recyclability of the PDA@ZIF-67}

The adsorption efficiency of an adsorbent after recycling has emerged as an important and crucial factor. In fact, in the first series, a fresh catalyst was used and the adsorption percentage of methylene blue was measured at $\mathrm{pH}=2$ and concentration of 7.5 after 8 minutes, which showed red peaks before the adsorption effect and blue peaks after the adsorption effect. As shown in Figure 12, the PDA@ZIF-67 was able to remove up to $62.1 \%$ of MB after six successive runs. 


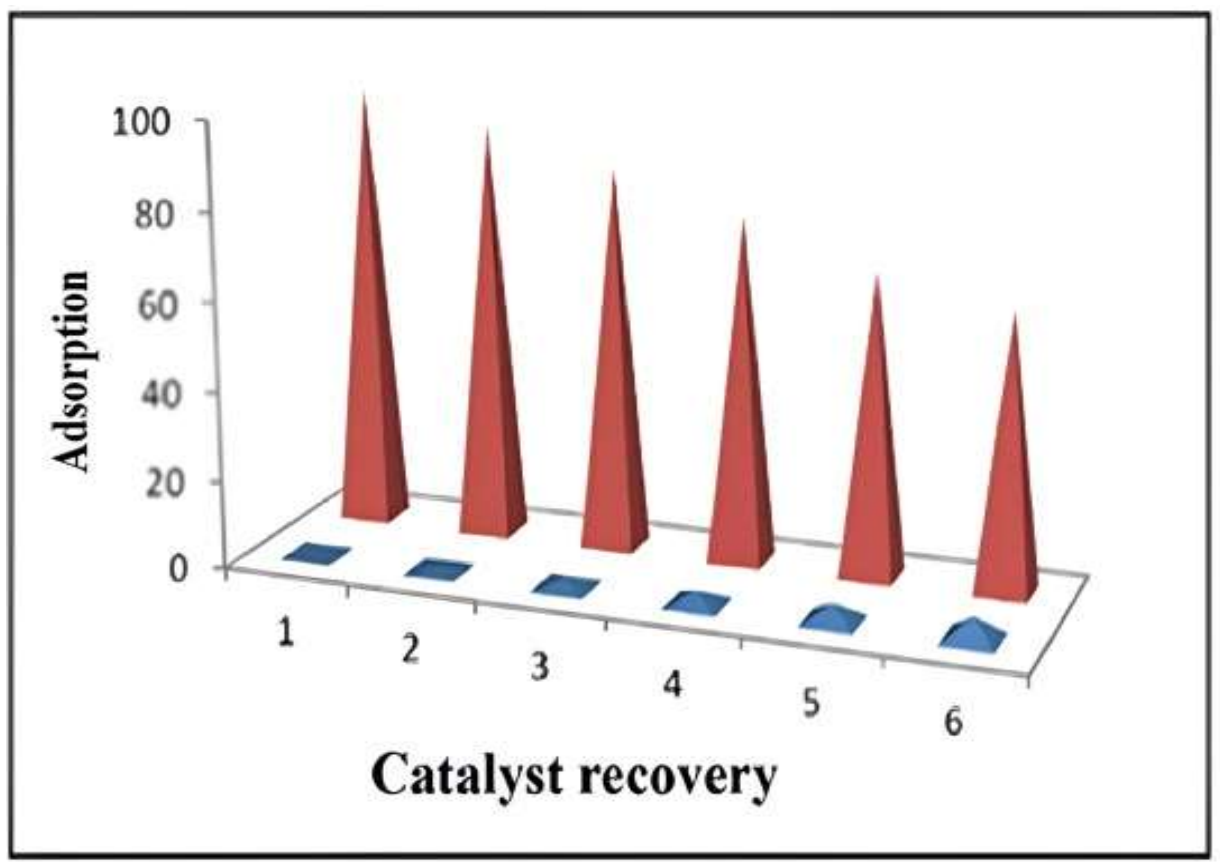

Figure 12- Red peak indicates adsorption of methylene blue before adsorbent and blue peaks indicate adsorption of methylene blue after adsorption by PDA@ZIF-67 to 6 times recovery

\section{Adsorption kinetics and isotherms}

Study of the adsorption kinetics is very important to predict the adsorption mechanisms that control the pollutants removal and the retention time of adsorbed species. The adsorption kinetics can be explored by some kinetic models such as pseudo-first-order (PFO) [30], pseudo-secondorder (PSO) [30], and intra-particle kinetics [20].

The pseudo-first-order equation is described as equation (1);

$\mathrm{q}_{\mathrm{t}}=\mathrm{q}_{\mathrm{e}}\left(1-\exp ^{\left.-\mathrm{k}_{1} \mathrm{t}\right)} \quad\right.$ Equation 1

where, the unit of rate constant $\left(\mathrm{k}_{1}\right)$ is $1 / \mathrm{min}$., and $\mathrm{t}$ is the adsorption time.

The Pseudo-second-order equation can be explained by equation (2);

$\mathrm{q}_{\mathrm{t}}=\mathrm{k}_{2} \mathrm{q}_{\mathrm{e}}{ }^{2} \mathrm{t} / 1+\mathrm{k}_{2} \mathrm{q}^{\mathrm{t}} \quad$ Equation 2

where, $\mathrm{k}_{2}$ represents the rate constant of the pseudo-second-order equation (g/mg.min). The initial absorption velocity can be obtained using the values of $\mathrm{k}_{2}$ and qe in the top equation.

The intramolecular diffusion model follows the equation 3; 
where, $\mathrm{C}$ is related to the thickness of the boundary layer. The rate constant of intramolecular diffusion $\left(\mathrm{k}_{\mathrm{i}}\right)$ is $\mathrm{min} / 1$. Table 2 shows the calculated parameters for the adsorption of MB by PDA@ZIF-67.

Table 2. Kinetic parameters obtained from traditional models for MB adsorption (5 mg $\mathrm{L}^{-1)}$

\begin{tabular}{lllllllll}
\hline \multicolumn{3}{c}{ Pseudo first-order } & \multicolumn{4}{c}{ Pseudo second-order } & \multicolumn{3}{c}{ Intra-particle diffusion } \\
\hline $\mathrm{q}_{\mathrm{e}}$ & $\mathrm{K}_{1}$ & $\mathrm{R}^{2}$ & $\mathrm{q}$ & $\mathrm{K}_{2}$ & $\mathrm{R}^{2}$ & $\mathrm{~K}_{\text {diff }}$ & $\mathrm{C}$ & $\mathrm{R}^{2}$ \\
33.861 & 0.464 & 0.9541 & 81.3 & 0.018 & 0.9997 & 9.8578 & 48.258 & 0.9661 \\
\hline
\end{tabular}

The obtained $\mathrm{q}_{\mathrm{e}}$ values from the pseudo-first-order kinetics model for MB adsorption is not consistent with the experimental data. The q-theoretic data values follow the pseudo-secondorder model. According to the model, the intra-particle diffusion of the adsorption process creates a linear diagram for $\mathrm{q}_{\mathrm{t}} \mathrm{vs} . \mathrm{t}^{0.5}$ implying that if the lines pass through the origin, the speed control step is shown with this model (Figure 13). 

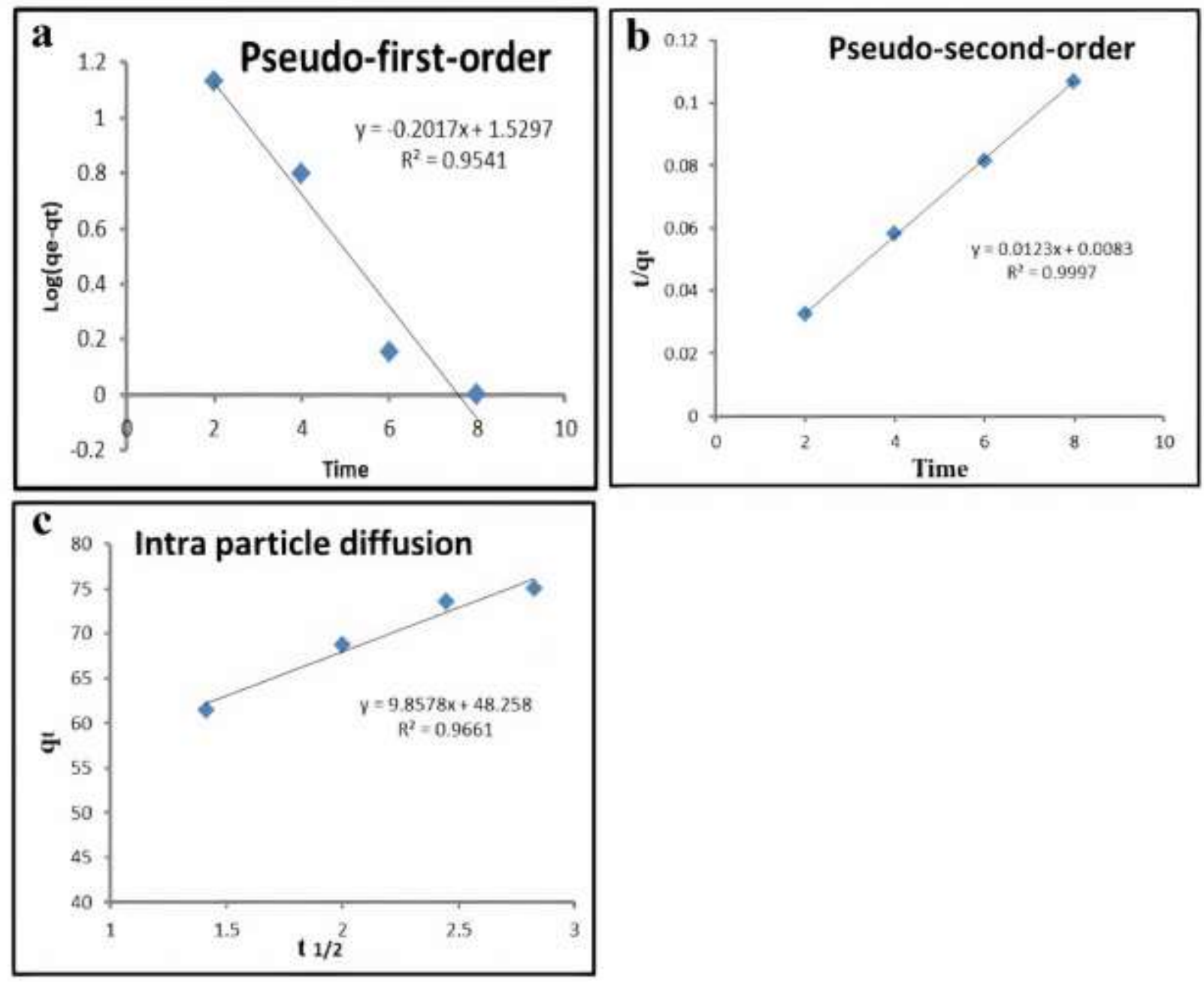

Figure 13--(a-c) Pseudo-first order, pseudo-second order, and intra-particle model for dye adsorption on PDA@ZIF-67 utilizing linear equation

The highest and lowest $\mathrm{R}^{2}$ values belong to the pseudo-second-order and pseudo-first-order kinetics, respectively. Therefore, the adsorption of MB on PDA@ZIF-67 best fits to the pseudosecond order model. The results indicate that the rate-limiting phase of MB adsorption is the chemical adsorption phase of capacitance forces through the exchange or sharing of electrons between the adsorbent and the adsorbent. To better understand the mechanism of the adsorption process, adsorption isotherms were used. Therefore, Langmuir, Freundlich, and Temkin isotherms were selected as the three most important isotherm models in this study. 
The adsorption process was studied at a constant temperature. Adsorption isotherms are mathematical relationships that show the amount of adsorbed molecules on the surface of the adsorbent. The adsorption properties of PDA@ZIF-67 toward MB at different concentrations of 2.5 to $20 \mathrm{mg} / \mathrm{L}$ was investigated.

\section{A) Langmuir adsorption isotherm:}

The Langmuir adsorption isotherm is one of the adsorption isotherms, which was developed by Irwin Langmuir in 1916 [9].

The Langmuir equation is as follows:

$\frac{C_{e}}{q_{e}}=\frac{C_{e}}{q_{\max }}+\frac{1}{q_{\max } k_{l}} \quad$ Equation 4

Where, $\mathrm{k}_{\mathrm{L}}$ denotes Langmuir constant $(\mathrm{mg} / \mathrm{L})$ and it means adsorption capacity at a pure level.

According to the Langmuir equation, the obtained values for $\mathrm{K}_{\mathrm{L}}$ and $\mathrm{q}_{\max }$ were $2.0833 \mathrm{~L} / \mathrm{mg}$, and $100 \mathrm{mg} / \mathrm{g}$, respectively.

\section{B) Freundlich adsorption isotherm}

The Freundlich equation is as follows [23]:

$\ln q_{e}=\frac{1}{n} \ln C_{e}+\ln K_{f} \quad$ Equation 5

where, $K_{f}$ is the Freundlich constant $(\mathrm{mg} / \mathrm{g})$, which represents the approximate index of Freundlich surface adsorption, and $1 / \mathrm{n}$ is the factor of surface adsorption strength during the adsorption process. The value of $\mathrm{K}_{\mathrm{f}}$ based on the Freundlich equation was found to be 56.053 $\mathrm{mg} / \mathrm{g}$.

\section{C) Temkin adsorption isotherm}

The equation of Temkin described in the literature [25] is as follows:

$q_{e}=\frac{R T}{b_{T}} \ln A_{T}+\left(\frac{R T}{b_{T}}\right) \ln C_{e} \quad$ Equation 6

where, qe is the amount of solute adsorbed per unit weight of adsorbent $(\mathrm{mg} / \mathrm{g})$, Ce is the equilibrium concentration of $\mathrm{MB}(\mathrm{mg} / \mathrm{L}), \mathrm{R}, \mathrm{A}, \mathrm{T}$ and $\mathrm{b}$ are the Temkin constants. According to the obtained parameters, the Langmuir, Freundlich and Temkin diagrams are drawn and 
interpreted. According to the diagrams (Figure 14), it can be concluded that the adsorbent follows the Langmuir adsorption isotherm (with high values of $\mathrm{R}^{2}$ ).

Table 3. The Langmuir, Freundlich and Temkin isotherms model constants and their correlation coefficients $\mathrm{R}^{2}$ for the sorption of MB on PDA@ZIF-67.

\begin{tabular}{cccccccccc}
\hline \multicolumn{3}{c}{ Langmuir } & \multicolumn{3}{c}{ Freundlich } \\
\hline $\begin{array}{c}\mathrm{Q}_{0} \\
(\mathrm{mg} / \mathrm{g})\end{array}$ & $\mathrm{b}(\mathrm{L} / \mathrm{mg})$ & $\mathrm{R}^{2}$ & $\mathrm{~K}_{\mathrm{f}}(\mathrm{mg} / \mathrm{g})$ & $\mathrm{n}(\mathrm{g} / \mathrm{L})$ & $\mathrm{R}^{2}$ & $\mathrm{~K}_{\mathrm{t}}(\mathrm{mg} / \mathrm{g})$ & $\mathrm{B}$ & $\mathrm{R}^{2}$ \\
101.3772 & 0.2460 & 0.9328 & 5112.109 & 4.8247 & 0.9066 & 0.8665 & 13.3558 & 0.8029 \\
\hline
\end{tabular}

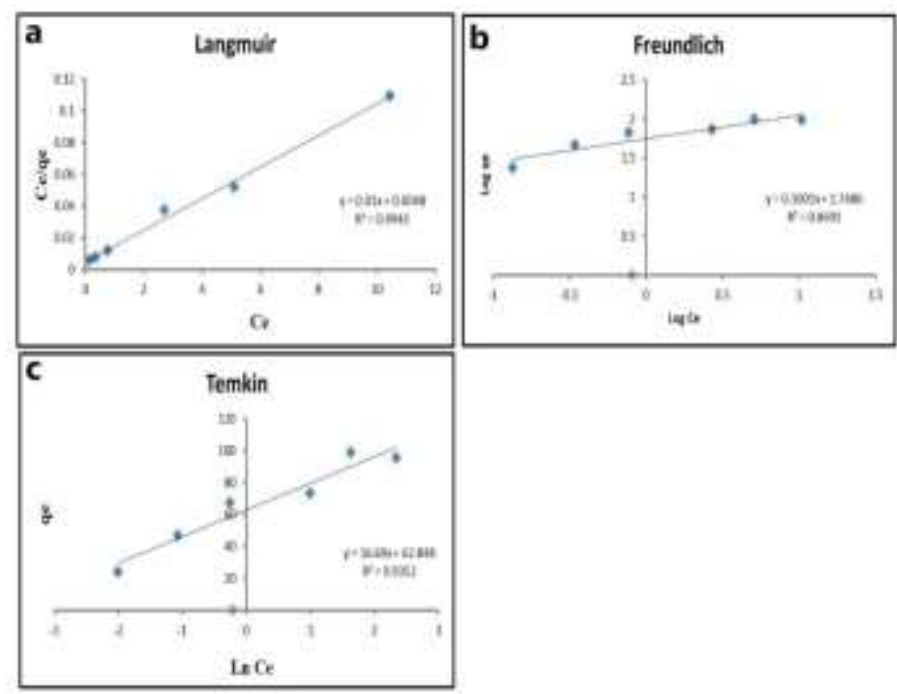

Figure 14-(a-c) Langmuir, Freundlich, and Temkin isotherms for MB adsorption onto PDA@ZIF-67 (Initial concentration of 7.5ppm, 65 oC).

\section{Thermodynamics}

The thermodynamic parameters were taken into account to characterize the adsorption operation on account of the 1 mole transfer of a solute from an aqueous solution on the solid-liquid interface. The empirical outcomes for adsorption of MB dye on PDA@ZIF-67 catalyst were applied at five various temperatures $(298,308,318,328$, and $338 \mathrm{~K})$ to evaluate the thermodynamics parameters like Gibbs free energy $\left(\Delta \mathrm{G}^{\circ}, \mathrm{kJ} / \mathrm{mol}\right)$, entropy change $\left(\Delta \mathrm{S}^{\circ}, \mathrm{J} / \mathrm{mol}\right.$ $\mathrm{K})$, and enthalpy change $\left(\Delta H^{\circ}, \mathrm{kJ} / \mathrm{mol}\right)$. The aforementioned parameters were calculated utilizing Van't Hoffs equation.

$\ln K_{d}=\frac{\Delta \mathrm{S}^{\circ}}{R}-\frac{\Delta \mathrm{H}^{\circ}}{R T}$

Equation 8 
Table 3. Thermodynamic parameters of MB adsorption on PDA@ZIF-67

\begin{tabular}{|l|l|l|l|}
\hline \multirow{2}{*}{ Temperature (K) } & \multicolumn{3}{|c|}{ Thermodynamic parameters } \\
\cline { 2 - 4 } & $\Delta G^{\circ}{ }_{\mathrm{a}}\left(\mathrm{KJ} \mathrm{mol}^{-1}\right)$ & $\Delta{H^{\circ}}_{\mathrm{a}}\left(\mathrm{KJ} \mathrm{mol}^{-1}\right)$ & $\Delta S_{\mathrm{a}}^{\circ}\left(\mathrm{J} \mathrm{mol}^{-1} \mathrm{~K}^{-1}\right)$ \\
\hline 298.15 & -11.0567 & 30.6512 & 140.132 \\
\hline 308.15 & -12.6887 & & \\
\hline 318.15 & -13.8791 & & \\
\hline 328.15 & -15.2529 & & \\
\hline 338.15 & -16.7788 & & \\
\hline
\end{tabular}

Where, $\mathrm{R}, \mathrm{T}$, and $\mathrm{K}_{\mathrm{L}}$ refer to the gas constant $\left(8.314 \mathrm{~J} \mathrm{~mol}^{-1} \mathrm{~K}^{-1}\right)$, temperature $(\mathrm{K})$, and Langmuir isotherm constant $\left(\mathrm{L} \mathrm{g}^{-1}\right)$, respectively. By plotting $\log \mathrm{K}_{\mathrm{L}}$ against $\mathrm{T}^{-1}$ the values of $\Delta \mathrm{S}^{\circ}$ and $\Delta \mathrm{H}^{\circ}$ whereas $\Delta \mathrm{G}^{\circ}$ were determined utilizing the Equation 9. Table 5 reveals the obtained thermodynamic parameters.

$\Delta \mathrm{S}^{\circ}>0$ implies that the MB molecules adsorption is randomly increased at the solid/solution border of the adsorbent. Consequently, throughout the enhancement of MB adsorbed on the adsorbent surface, the amount of MB in solution decreases, and the freedom of solvent particles and PDA@ZIF-67 interface accelerates. Therefore, there is a strong affinity between the PDA@ZIF-67 particles and MB molecules [26].

Additionally, the endothermic reaction can be corroborated with the improving adsorption capacity correlated with the increase in temperature. $\Delta \mathrm{G}^{\circ}<0$ indicates that the process of adsorption is practical at $\mathrm{RT}$ and the increase of $\Delta \mathrm{G}^{\circ}$ values with growing temperature signifies which the adsorption process of MB on the PDA@ZIF-67 is more spontaneous at higher temperatures [38].

On the other hand, the $\Delta \mathrm{H}^{\circ}$ magnitude can provide an idea about the kind of adsorption. The evolved heat during physical adsorption is of the same magnitude order as the heats of condensation, for instance, $2.1-20.9 \mathrm{~kJ} \mathrm{~mol}^{-1}$, whereas the heats of chemisorption generally fall between $80-200 \mathrm{~kJ} \mathrm{~mol}^{-1}[38]$. In this research, the $\Delta \mathrm{H}^{\circ}$ value was $30.6512 \mathrm{~kJ} \mathrm{~mol}^{-1}$ that signifies that the adsorption of MB should be considered as chemisorption [39]. It has been observed that 
the adsorbent capacity was mainly a function of the initial concentration of $\mathrm{MB}$, and $\mathrm{qm}$ generally increases with increasing initial concentration of MB [38].

Table 4. A comparison of the obtained results for PDA@ZIF-67 with other common adsorbents reported in the literature.

\begin{tabular}{|c|c|c|c|}
\hline Adsorbent & $\mathrm{q}(\mathrm{mg} / \mathrm{g})$ & Experimental Condition & Reference \\
\hline PDA@ZIF-67 & 100 & $\begin{array}{l}\mathrm{pH} 2 \\
\mathrm{CA}=7.5 \mathrm{mg} / \mathrm{L} \\
\text { Contact time }=8 \mathrm{~min} \\
\text { Temprature }=65^{\circ} \mathrm{C} \\
\mathrm{m}=10 \mathrm{mg}\end{array}$ & Present work \\
\hline MOF1 & 102.4 & $\begin{array}{l}\mathrm{pH} 7 \\
\mathrm{CA}=10 \\
\text { Contact time }=2 \mathrm{~h} \\
\text { Temprature }=25^{\circ} \mathrm{C}\end{array}$ & [44] \\
\hline Laboratory paper & 24 & $\begin{array}{l}\mathrm{pH} \text { Nature } \\
\mathrm{CA}=40 \\
\text { Contact time }=2 \mathrm{~h} \\
\text { Adsorbent }=0.25 \mathrm{~g} \\
\text { Temprature }=30^{\circ} \mathrm{C}\end{array}$ & [14] \\
\hline Fe3O4@MIL-100(Fe) & 73.80 & $\begin{array}{l}\mathrm{pH} 9 \\
\mathrm{CA}=60 \mathrm{mg} / \mathrm{L} \\
\text { Contact time }=120 \mathrm{~min} \\
\mathrm{~m}=100 \mathrm{mg} \\
\text { Temprature }=45^{\circ} \mathrm{C}\end{array}$ & [43] \\
\hline $\begin{array}{l}\text { Magnetite@silica@pectin } \\
\text { hybrid nanocomposite }\end{array}$ & 85.18 & $\begin{array}{l}\text { pH } 8 \\
\mathrm{CA}=100 \\
\text { Contact time }=120 \mathrm{~min} \\
\text { Temprature }=25^{\circ} \mathrm{C}\end{array}$ & [4] \\
\hline Parthenium hysterphorus & 39.7 & $\begin{array}{l}\mathrm{pH} 7 \\
\mathrm{CA}=0.4 \mathrm{~g} / 100 \mathrm{~mL} \\
\text { Contact time }=60 \mathrm{~min}\end{array}$ & [24] \\
\hline $\begin{array}{l}\text { CuO loaded Activated } \\
\text { Carbon } 1\end{array}$ & 10.54 & $\begin{array}{l}\mathrm{pH} 6 \\
\mathrm{CA}=50 \mathrm{mg} / \mathrm{L} \\
\text { Contact time }=4.5 \mathrm{~min} \\
\text { Adsorbent }=1.1 \mathrm{~g} / \mathrm{L} \\
\text { Temprature }=\text { room }\end{array}$ & [13] \\
\hline $\begin{array}{l}\text { Fly ash geopolymer } \\
\text { powder }\end{array}$ & 50.7 & $\begin{array}{l}\mathrm{pH} \text { higher } \\
\mathrm{CA}=75 \mathrm{mg} / \mathrm{L} \\
\text { Contact time }=2 \mathrm{~h} \\
\text { Adsorbent }=40 \mathrm{mg} \\
\text { Temprature }=25^{\circ} \mathrm{C}\end{array}$ & [15] \\
\hline Fe-BDC MOF & 8.65 & $\begin{array}{l}\mathrm{pH} 9 \\
\mathrm{CA}=5 \mathrm{mg} / \mathrm{L} \\
\text { Contact time }=24 \mathrm{~h} \\
\text { Adsorbent }=2.5 \mathrm{~g} / \mathrm{L} \\
\text { Temprature }=323 \mathrm{~K}\end{array}$ & [3] \\
\hline
\end{tabular}




\section{Conclusion}

In the present work, a new hybrid crystalline porous material was synthesized by doping ZIF-67 with PDA. The resultant composite was used as an adsorbent to remove MB dye from aqueous solution. The PDA@ZIF-67 exhibited an excellent adsorption performance in removal of MB dye. The optimal conditions for the maximum adsorption efficiency was found to be dye concentration of $7.5 \mathrm{ppm}, \mathrm{pH} \mathrm{2,}$ 10 mg of PDA@ZIF-67 dosage, at $338 \mathrm{~K}$. The Langmuir isotherm with a maximum adsorption of MB $\mathrm{mg} / \mathrm{g}$ was identified as a more favorable model to describe the adsorption process. Based on the results, it can be concluded that the PDA@ZIF-67 can be used as an effective adsorbent to remove MB from aqueous solutions.

Declarations: The authors of this manuscript declare no conflict of interest.

\section{References}

1. Albatrni H, Qiblawey H, El-Naas MH (2021) Comparative study between adsorption and membrane technologies for the removal of mercury. Sep Purif Technol257:117833

2. Aleem M, Cao J, Li C et al. (2020) Coagulation-and adsorption-based environmental impact assessment and textile effluent treatment. Water Air Soil Pollut 231:1-8

3. Arora C, Soni S, Sahu S et al. (2019) Iron based metal organic framework for efficient removal of methylene blue dye from industrial waste. J. Mol. Liq. 284:343-352

4. Attallah OA, Al-Ghobashy MA, Nebsen M et al. (2016) Removal of cationic and anionic dyes from aqueous solution with magnetite/pectin and magnetite/silica/pectin hybrid nanocomposites: kinetic, isotherm and mechanism analysis. RSC Adv 6:11461-11480

5. Atun G, Ortaboy S, Tüzün E et al. (2021) A comparison of anionic and cationic dye removal efficiency of industrial bauxite waste red-mud. J Dispers Sci Technol:1-13

6. Batul R, Bhave M, J Mahon P et al. (2020) Polydopamine nanosphere with in-situ loaded gentamicin and its antimicrobial activity. Molecules 25:2090

7. Bioumy SA, Ahmed RA, Fekry AM (2020) Electrochemical corrosion behavior of graphene oxide/chitosan/silver nanoparticle composite coating on stainless steel utensils in aqueous media. J Bio Tribocorros 6:1-14

8. Chai J-B, Au P-I, Mubarak NM et al. (2020) Adsorption of heavy metal from industrial wastewater onto low-cost Malaysian kaolin clay-based adsorbent. Environ Sci Pollut Res 27:13949-13962

9. Chen L, Zhang X, Cheng X et al. (2020) The function of metal-organic frameworks in the application of MOF-based composites. Nanoscale Adv 2:2628-2647

10. Chen M, Shen Y, Xu L et al. (2020) Synthesis of a super-absorbent nanocomposite hydrogel based on vinyl hybrid silica nanospheres and its properties. RSC Adv 10:41022-41031 
11. Choi Y, Lee J-H, Kim K et al. (2021) Identification, quantification, and prioritization of new emerging pollutants in domestic and industrial effluents, Korea: Application of LC-HRMS based suspect and non-target screening. J Hazard Mater 402:123706

12. Dahiya D, Nigam PS (2020) Waste management by biological approach employing natural substrates and microbial agents for the remediation of dyes' wastewater. Appl Sci 10:2958

13. Dashamiri S, Ghaedi M, Dashtian K et al. (2016) Ultrasonic enhancement of the simultaneous removal of quaternary toxic organic dyes by $\mathrm{CuO}$ nanoparticles loaded on activated carbon: Central composite design, kinetic and isotherm study. Ultrason Sonochem 31:546-557

14. Durairaj A, Sakthivel T, Ramanathan S et al. (2019) Conversion of laboratory paper waste into useful activated carbon: a potential supercapacitor material and a good adsorbent for organic pollutant and heavy metals. Cellulose 26:3313-3324

15. Ghaedi M, Hajjati S, Mahmudi Z et al. (2015) Modeling of competitive ultrasonic assisted removal of the dyes - Methylene blue and Safranin-O using Fe3O4 nanoparticles. Chem Eng J 268:28-37

16. Guillossou R, Le Roux J, Brosillon S et al. (2020) Benefits of ozonation before activated carbon adsorption for the removal of organic micropollutants from wastewater effluents. Chemosphere 245:125530

17. Hassanpour A, Zamanfar M, Ebrahimiasl S et al. (2021) Dopamine Drug Adsorption on the Aluminum Nitride Single-Wall Nanotube: Ab initio Study. Arab J Sci Eng:1-8

18. Hızal J, Yılmazoğlu M (2021) Montmorillonite clay composite for heavy metal removal from water. In: Green Adsorbents to Remove Metals, Dyes and Boron from Polluted Water. Springer Sci. Rev. 93-112

19. Ho C-C, Ding S-J (2013) The pH-controlled nanoparticles size of polydopamine for anti-cancer drug delivery. Journal of Materials Science: Mater Med 24:2381-2390

20. Hooshyar SP, Panahi HA, Moniri E et al. (2021) Tailoring a new hyperbranched PEGylated dendrimer nano-polymer as a super-adsorbent for magnetic solid-phase extraction and determination of letrozole in biological and pharmaceutical samples.J. Mol. Liq. 338:116772

21. Huang L, Miao J, Shuai Q (2020) Carboxyl-functionalized magnetic porous organic polymers as efficient adsorbent for wastewater remediation. J Taiwan Inst Chem Eng 109:97-102

22. Khan A, Ali M, Ilyas A et al. (2018) ZIF-67 filled PDMS mixed matrix membranes for recovery of ethanol via pervaporation. Sep Purif Technol 206:50-58

23. Kuśmierek K, Świątkowski A, Skrzypczyńska K et al. (2021) Adsorptive and Electrochemical Properties of Carbon Nanotubes, Activated Carbon, and Graphene Oxide with Relatively Similar Specific Surface Area. Materials 14:496

24. Lata H, Garg VK, Gupta RK (2007) Removal of a basic dye from aqueous solution by adsorption using Parthenium hysterophorus: An agricultural waste. Dyes Pigm 74:653-658

25. Lee HA, Park E, Lee $H$ (2020) Polydopamine and its derivative surface chemistry in material science: a focused review for studies at KAIST. Adv Mater 32:1907505

26. Li M, Sun P, Wu Q et al. (2018) Core-shell magnetic metal-organic framework molecularly imprinted nanospheres for specific adsorption of tetrabromobisphenol A from water. Environ Sci: Nano 5:2651-2662

27. Li Y, Jin Z, Zhao T (2020) Performance of ZIF-67-Derived fold polyhedrons for enhanced photocatalytic hydrogen evolution. J Chem Eng 382:123051

28. Lü Y, Zhan W, He Y et al. (2014) MOF-templated synthesis of porous Co3O4 concave nanocubes with high specific surface area and their gas sensing properties. ACS Appl Mater Interfaces 6:4186 4195 
29. Luo H, Gu C, Zheng W et al. (2015) Facile synthesis of novel size-controlled antibacterial hybrid spheres using silver nanoparticles loaded with poly-dopamine spheres. Rsc Adv 5:13470-13477

30. Mohammadinezhad A, Marandi GB, Farsadrooh M et al. (2018) Synthesis of poly(acrylamide-coitaconic acid)/MWCNTs superabsorbent hydrogel nanocomposite by ultrasound-assisted technique: Swelling behavior and $\mathrm{Pb}$ (II) adsorption capacity. Ultrason Sonochem 49:1-12

31. Piai L, Blokland M, Van Der Wal A et al. (2020) Biodegradation and adsorption of micropollutants by biological activated carbon from a drinking water production plant. J. Hazard. Mater 388:122028

32. Qiu M, He C (2019) Efficient removal of heavy metal ions by forward osmosis membrane with a polydopamine modified zeolitic imidazolate framework incorporated selective layer. J. Hazard. Mater. 367:339-347

33. Sahu S, Pahi S, Tripathy S et al. (2020) Adsorption of methylene blue on chemically modified lychee seed biochar: Dynamic, equilibrium, and thermodynamic study. J Mol Liq 315:113743

34. Shahbakhsh M, Noroozifar M (2018) Poly (dopamine quinone-chromium (III) complex) microspheres as new modifier for simultaneous determination of phenolic compounds. Biosens. Bioelectron. 102:439-448

35. Shindhal T, Rakholiya P, Varjani S et al. (2021) A critical review on advances in the practices and perspectives for the treatment of dye industry wastewater. Bioeng. Bugs 12:70-87

36. Sohrabnezhad S, Pourahmad A, Karimi MF (2020) Magnetite-metal organic framework core@ shell for degradation of ampicillin antibiotic in aqueous solution. J Solid State Chem 288:121420

37. Tony M (2020) Zeolite-based adsorbent from alum sludge residue for textile wastewater treatment. Int J Environ Sci Techno 17:2485-2498

38. Utsev J, Iwar R, Ifyalem K (2020) Adsorption of methylene blue from aqueous solution onto delonix regia pod activated carbon: Batch equilibrium isotherm, kinetic and thermodynamic studies agricult. wastes 4:18-19

39. Vieira WT, De Farias MB, Spaolonzi MP et al. (2020) Removal of endocrine disruptors in waters by adsorption, membrane filtration and biodegradation. A review. Environ Chem Lett 18:11131143

40. Vučković N, Nikodijević M, Đorđević D (2021) The study of direct dye sorption on flax fibers during dyeing. Chem. Ind. Chem. Eng. Q 27:255-263

41. Wang J, Wang S (2020) Reactive species in advanced oxidation processes: Formation, identification and reaction A. J Chem Eng:126158

42. Wang K, Wei T, Li Y et al. (2021) Flocculation-to-adsorption transition of novel salt-responsive polyelectrolyte for recycling of highly polluted saline textile effluents. J Chem Eng 413:127410

43. Yang Q, Zhao Q, Ren S et al. (2016) Fabrication of core-shell Fe304@MIL-100(Fe) magnetic microspheres for the removal of $\mathrm{Cr}(\mathrm{VI})$ in aqueous solution. J. Solid State Chem 244:25-30

44. Yi F-Y, Li J-P, Wu D et al. (2015) A Series of Multifunctional Metal-Organic Frameworks Showing Excellent Luminescent Sensing, Sensitization, and Adsorbent Abilities. Chem - A Eur J 21:1147511482

45. Yi FY, Li JP, Wu D et al. (2015) A series of multifunctional metal-organic frameworks showing excellent luminescent sensing, sensitization, and adsorbent abilities. Chem - A Eur J 21:1147511482

46. Yu F, Bai X, Liang M et al. (2021) Recent progress on metal-organic framework-derived porous carbon and its composite for pollutant adsorption from liquid phase. Chem Eng J 405:126960

47. Zhang M, Zhang Z, Peng Y et al. (2020) Novel cationic polymer modified magnetic chitosan beads for efficient adsorption of heavy metals and dyes over a wide $\mathrm{pH}$ range. Int J Biol Macromol 156:289-301 
